\title{
MISVATTINGEN OMTRENT DE STAATKUNDIGE ONTWIKKELING VAN SURINAME
}

Er wordt de laatste tijd, vooral sedert de totstandkoming van het Statuut, begrijpelijkerwijs veel aandacht geschonken aan de staatkundige evolutie van Suriname, waarbij de nodige vergelijkingen worden gemaakt tussen vroeger en nu. Men stelt het als regel zo voor, dat men hier eerst voor zeer lange tijd leefde in slaafs kolonialisme. Pas in de tweede helft van de vorige eeuw zou hierin enige verandering zijn gekomen. Geleidelijk aan wijzigde zich toen de koloniale verhouding met het moederland eerst heel langzaam, maar in de jaren na de laatste wereldoorlog in een snel tempo - om tenslotte uit te groeien tot een gelijkwaardig deelgenootschap van Suriname met Nederland binnen het Koninkrijk Nieuwe Stijl.

Genoemde voorstelling is evenwel historisch beslist niet juist. Suriname heeft de staatkundige ladder niet zo maar trap voor trap van onder naar boven doorlopen na eerst lange tijd op de bodem van de koloniale put te zijn blijven staan. Het is veeleer zo, dat Suriname al heel vroeg in zijn geschiedenis een uitzonderlijk hoge sport van die ladder bereikte, waarop het zich ruim een eeuw lang heeft kunnen handhaven. Na de Napoleontische tijd echter is Suriname als het ware van de ladder afgetuimeld tot een ongekend dieptepunt, is daar een 5o-tal jaren blijven liggen, om eindelijk weer moeizaam van onder af aan naar boven te klimmen. Wij zullen hieronder nader op deze ontwikkeling ingaan, in het bijzonder op de eerste fase.

De kiem van de bijzondere politieke vrijheden van de Surinaamse kolonisten werd feitelijk reeds gelegd in de beginjaren van de eerste volksplanting onder WilloughBy. Al heel spoedig na de geslaagde kolonisatie van $165 \mathrm{I}$ was deze namelijk gedwongen Suriname weer te verlaten om in Engeland erkenning van zijn 
rechten op de kolonie te verkrijgen. Hij had een wettige titel nodig om zijn gezag in Suriname te grondvesten, en deze titel kon slechts aan zijn souvereine vorst worden ontleend. Na veel moeite en langdurige onderhandelingen werd pas in 1662 het verlangde patent door de Koning van Engeland verleend.

Ondertussen waren de kolonisten in Suriname betrekkelijk lange tijd aan hun lot overgelaten geweest. $\mathrm{Zij}$ hadden uiteindelijk ook zelf in hun bestuur voorzien. Een vertegenwoordigende vergadering werd ingesteld, die in 1657 een eigen gouverneur benoemde, bijgestaan door een Raad. Op welke wijze het bestuur in feite toen werd uitgeoefend, is niet geheel duidelijk. Aangenomen mag worden, dat de heren kolonisten zich vele vrijheden aanmatigden en zoveel mogelijk deden en lieten wat zij maar wilden. Toen dan ook WilloughBy in r664 met zijn patent in Suriname terugkwam, werd hij niet bepaald enthousiast ontvangen. Openlijk werd door de kolonisten bezwaar gemaakt tegen hun - nu officiële - afhankelijke positie als zgn. freeholders van WilloughBY, alhoewel zulk een positie in die jaren volkomen normaal was. WilloughBY heeft gedurende zijn aanwezigheid in Suriname nog getracht de ontevredenheid wat tot bedaren te brengen, maar hij kon niet voorkomen, dat in r665 een 200-tal personen uit protest de kolonie verliet. Aan de verwende kolonisten zullen enige concessies zijn gedaan, want aan een kolonie zonder kolonisten had een patroon nu eenmaal niets.

Toen de Zeeuwen in r667 Suriname veroverden, troffen zij dus een volksplanting aan, waar de kolonisten nogal ongebruikelijke politieke en andere vrijheden genoten. Aan deze kolonisten, die gewend geraakt waren aan een 'representative government', werd ook maar door het Zeeuwse bestuur een zekere medezeggenschap gegeven in policie (bestuur) en in justitie. Reeds in I669 werd door Gouverneur LICHTENBERGH zowel een Raad van Politie of Politieke Raad als een Raad van Justitie ingesteld, elk bestaande uit 5 leden. Deze Raden werden echter nu niet gekozen, maar door de gouverneur benoemd. $\mathrm{Zij}$ zijn later, in I68o, tot één college samengevoegd. Suriname vormde door deze kolonistenraden een uitzondering onder de Nederlandse koloniën van die dagen, waar bestuur en rechtspraak normaliter geheel bij het ambtelijk apparaat berustten.

De Provincie Zeeland bezat bij de verovering van Suriname evenmin een octrooi als WilloughBy dat destijds bij zijn kolo- 
nisatie had gehad. Er bestond wel een octrooi voor de WestIndische Compagnie van I62I en een charter voor de Zeeuwse Kamer van de W.I.C. van 1628 met betrekking tot de kolonisatie van tropisch Amerika, maar met de Compagnie wenste Zeeland niets te maken te hebben. Genoemde regelingen zijn daarom nooit van toepassing geweest op Suriname. Zeeland achtte zijn bevoegdheden in overeenstemming met het algemeen Regeringsreglement, dat in I629 door de Staten-Generaal voor alle WestIndische bezittingen van de W.I.C. was vastgesteld (Ordre van Regieringe, soo in Policie als Justitie in de Plaetsen verovert en te veroveren in West-Indiē).

Het gezag van Zeeland over Suriname is zeer betwist geweest en tijdens het Zeeuwse bewind van I667 tot 1683 is er ook nimmer een vaste regeling voor het bestuur van Suriname tot stand gekomen. De Surinaamse volksplanting bleef daardoor in deze periode zijn bijzondere positie behouden. Na de liquidatie van de eerste W.I.C. in 1674 werden bovendien in de West geen nieuwe patroonschappen, dwz. afzonderlijke koloniale bezittingen onder particulier bestuur, in het leven geroepen. Alleen Suriname en Berbice bestonden toen nog als zodanig en zijn ook verder nog heel lang onder een eigen directie blijven voortbestaan.

In 1682 werd de uitzonderingspositie van Suriname definitief bevestigd door een bijzonder octrooi. Zeeland had namelijk, teleurgesteld in de gestelde verwachtingen, zijn aanspraken op Suriname tenslotte toch te koop aangeboden aan de W.I.C., die in r682 op dit aanbod is ingegaan. In het begin van het daarop volgende jaar werd de kolonie aan de W.I.C. overgedragen. De Staten-Generaal - het souverein college van de Nederlandse Republiek - hadden het echter dienstig geacht om de nieuwe W.I.C., naast haar generaal octrooi van I674, verleend voor 25 jaar, nog een speciaal octrooi voor Suriname te verlenen, dat niet aan een tijdslimiet was gebonden. De Compagnie had de kolonie te aanvaarden met 'alsulken recht' als zij had op haar koloniën binnen haar invloedssfeer volgens het octrooi van r674 "met dat onderscheijdt alleen, dat de meer gemelte Compagnie ten eeuwigen dage niet bevoeght sal zijn, ofte vermogen eenighe de minste veranderinge te brengen in datgene, hetwelck bij de volgende (32) articulen bepaelt ende gelimiteerd staet". Dit betekende dus, dat het geldend gebleven Regeringsreglement van 1629 en het algemeen octrooi nu ook voor Suriname van kracht waren, maar alles voor zover het niet door het bijzonder Surinaams octrooi beperkt werd.

Blijkens de considerans was de reden voor het verlenen van 
het octrooi tweeledig. Ten eerste beoogde de Generaliteit Suriname zo spoedig mogelijk "tot een Considerabele Colonie van dese Landen" te maken. Er werd op gewezen, dat de ondernemer - de W.I.C. dus en later de Societeit - moest beginnen zich grote kosten te getroosten door de kolonisten hulp en assistentie te verlenen en hen privileges en een goed bestuur te verzekeren, om eerst na "vele jaren de vrugten van sijn uijtgeschoten geldt ende arbeid te genieten". Wanneer men de kolonisten aanstonds te zwaar zou belasten, zou de kolonie bij haar geboorte worden gesmoord, maar, "indien men de coloniërs in den aenbeginne sachtelijk handelt, mitsgaders dat men haer volkomen gerustheijdt geeft, datse voor het toekomende niet en sullen werden geëxactioneert ofte met schattingen uijtgeput", dan kan "aan een klein begin in korte tijdt een bijsonder en groot werck gemaeckt werden".

De tweede reden was "het voordeel ende welvaren door accres van Commercie ende Navigatie". Europese producten zouden bij verhoopt succes kunnen worden ingevoerd en 'rouwe' waren, d.i. suiker, tabak, enz., als retourvracht uit de kolonie worden meegenomen en verhandeld. De navigatie zou door meerdere werkverschaffing en "het aanqueecken van zeevarend volck en bequame Matrosen" worden bevorderd.

De Staten-Generaal wilden het belang van de kolonie gesteld zien boven de particuliere belangen van de W.I.C. De opbouw van Suriname stond zodanig op de voorgrond, dat de omschreven privileges niet alleen tegenover de Compagnie werden gewaarborgd, maar ook tegenover hen zelf als souverein. Het octrooi werd nl. verleend "sonder dat daervan oyt ofte oyt selfs bij de Machten van dese Landen, ten nadeel van de Opgesetenen aldaer sal moge werden gerecedeert".

Een van de voornaamste voorrechten was, dat het octrooi de kolonisten medezeggenschap in het bestuur waarborgde in aansluiting op de reeds bestaande situatie. Voor de oude Raad van Politie met benoemde leden kwam nu echter weer een gekozen vertegenwoordigend college met zelfs nog grotere bevoegdheden in de plaats. De Politieke Raad van het octrooi moest bestaan uit tenminste ro personen, die voor het leven werden benoemd. Voor elke raadsplaats werd door alle kolonisten bij meerderheid van stemmen uit de "aensienlijckste, verstandighste en moderaetste onder de Coloniërs", m.a.w. de invloedrijke planters, een tweetal gekozen, waaruit de gouverneur electie deed. Deze gou- 
verneur, die door de W.I.C. werd aangesteld na approbatie van de Generaliteit, had in alle zaken, zowel politiek als militair, het opperste gezag, maar was gehouden alle 'saken van eenig aanbelang' aan de Raad voor te leggen, welke bij meerderheid van stemmen de besluiten vaststelde. Deze besluiten, welke door de gouverneur moesten worden opgevolgd en "getrouwelijck ter executie geleyt werden", konden evenwel uitsluitend de uitvoering van de artikelen van het octrooi betreffen of zaken, waaromtrent de gouverneur geen bepaalde instructie had. Voor het overige waren gouverneur en raadsleden gehouden de orders en voorschriften van de W.I.C. op te volgen, die daardoor nog een aanzienlijke bestuursbevoegdheid overhield. De rechtspraak daarentegen was een zuivere koloniale aangelegenheid. De Raad van Politie werd met de criminele en een afzonderlijk te kiezen college met de civiele justitie belast.

Mocht na verloop van tijd blijken, dat de kolonie "te lastigh souden vallen" en de Bewindhebberen en hoofdparticipanten van de Compagnie van oordeel zijn, dat "het verder aenhouden [van de kolonie] soude wesen seer nadeelgh en ruineus", dan was het de W.I.C. gepermitteerd daarvan "bij abondonnement [sic] afstandt te doen, met al sulken effect, dat den Staet omtrent de besorginghe van de voorz. Colonie alsdan gehouden sal zijn ordres te stellen buyten de geseyde Compagnie".

Men dient zich goed voor ogen te stellen, dat bij het vaststellen van het Surinaamse octrooi geen scheiding van machten werd gemaakt. Montesouieu was zelfs nog niet eens geboren. De politieke rechten, die aan Suriname werden verleend, waren voor die tijd ook wel zeer ver strekkend. Het octrooi plaatste Suriname staatkundig gesproken ver boven andere koloniën. Wij zouden de status van Suriname in het toenmalig koloniaal bestel slechts kunnen vergelijken met die van een autonoom gebiedsdeel uit onze dagen. Suriname had verder alle kenmerken van een rechtspersoon. Behalve een eigen bestuur had het een eigen kas, die streng gescheiden werd gehouden van die van de Landsheer. De heffingen van de Compagnie waren door het octrooi zeer beperkt en betroffen voornamelijk handelsrechten, zoals uit- en ingaande rechten, alsmede recognitiën, waarmee het overheidsrecht van dit handelslichaam diende te worden erkend. Andere heffingen werden door het Surinaams bestuur vastgesteld voor en ten behoeve van de kolonie zelf. De positie van Suriname als kolonie volgens de normen van ongeveer 300 jaar terug was zeer zeker uitzonderlijk vrij en zelfstandig. 
In de praktijk kwam het Surinaams octrooi in de allereerste jaren niet geheel tot zijn recht. De W.I.C. had besloten de exploitatie van Suriname niet geheel alleen ter hand te nemen, maar aan de stad Amsterdam en aan CoRnelis van AERSSEN vaN SommelSDIJCK ieder een derde aandeel te verkopen. De drie aandeelhouders vormden tezamen het Genootschap (of de Societeit) van Suriname, dat als zodanig in I686 het beheer over Suriname van de W.I.C. overgedragen kreeg. Intussen was SoMMELSDIJCK reeds in 1683 door de W.I.C. als gouverneur naar Suriname gezonden. Deze was er de man niet naar om zich door kolonistenraden de wet te laten voorschrijven. Bij zijn aankomst in Suriname trof hij daar bovendien volgens zijn eigen woorden geen recht of gerechtigheid aan, ieder was zijn eigen meester en de planters waren oppermachtig. De bestaande PolitiekeRaad stelde eigen belangen voorop, terwijl corruptie hoogtij vierde. De Gouverneur was van oordeel, dat er zelfs in heel Suriname geen geschikte personen voor een raadsplaats te vinden waren. SOMMELSDIJCK trok zich dan ook bitter weinig van de Raad aan. Latere gouverneurs deden dit echter wel en in steeds toenemende mate. Doordat de rechtspraak berustte bij de koloniale Hoven, welke geheel uit invloedrijke planters waren samengesteld, konden maatregelen, welke tegen de belangen van de grondbezitters indruisten, moeilijk worden gehandhaafd. Het Hof van Politie beheerste op de duur de hele binnenlandse politiek en de belangen der planters liepen uiteraard niet parallel met die van de Societeit, welke door de gouverneur en zijn ambtenaren werd vertegenwoordigd. Het bestuur over Suriname was in het midden van de I8de eeuw zeker geen eenvoudige zaak, vooral ook, omdat er voor de administratie voortdurend geld te kort was. De heffingen van de Societeit waren strikt gelimiteerd en verschillende malen kon de Politieke Raad met succes op grond van het octrooi de invoering van nieuwe lasten beletten. Voor hun eigen koloniale kassen hadden de rijke planters echter evenmin veel over.

In I770 werd het Directorium van de Societeit gewijzigd toen de stad Amsterdam het aandeel van de erven SommeLsDiJck overnam. De Compagnie participeerde in I77I voor de helft in dit aandeel. Veel verschil bracht deze overheidswijziging niet. De W.I.C. was trouwens sterk in verval geraakt en er ging weinig meer van haar uit. Het zelfde kon gezegd worden van de Societeit, waarin immers de Compagnie ook voor de helft deelhebber was. Enige verandering kwam eigenlijk meer van de andere kant. 
$\mathrm{Na}$ de krach op de Amsterdamse beurs in 1773 kwamen de planters in financiële moeilijkheden en kort daarop begon de exodus van de gefailleerde afstammelingen van de oorspronkelijke kolonisten. In hun plaats kwamen de door de nieuwe plantage-eigenaren - meest Amsterdamse handelshuizen - uitgezonden administrateurs. Deze nieuwe bewoners van Suriname met hun vers uit Nederland meegebrachte ideeën namen langzamerhand ook de plaatsen in de Surinaamse Hoven in beslag. Opgegroeid als zij waren met het Corpus Juris en vol nieuwe denkbeelden vanwege de Franse revolutie, deden zij een andere wind waaien. $\mathrm{Zij}_{\mathrm{ij}}$ hadden bovendien, althans in het begin, geen directe belangen bij de economie van de kolonie, daar zij slechts bezittingen van anderen beheerden. In de regel gingen zij ook niet zelf op de hun toevertrouwde plantages wonen. Het eens zo welvarende Suriname ging hollende achteruit, maar het bestuur werd er gemakkelijker op. De angst voor de marrons en de noodzakelijkheid veel geld te besteden aan de binnenlandse en buitenlandse verdediging maakten de heren raadsleden ook veel bescheidener en soepeler. De invloed van de Raden op het bestuur begon zichtbaar af te nemen.

Het doorbreken van nieuwe ideeën en ook de critiek van de economen op de koloniale monopolies had ten gevolge, dat men in Nederland tegen het einde van de I8de eeuw het beginsel ging huldigen, dat koloniën uitsluitend door de Staat behoorden te worden bestuurd. In 1792 werd het octrooi van de W.I.C., die niet eens meer in staat was de interessen van haar schulden te betalen, niet meer verlengd. De Compagnie werd daarbij ontbonden en de directie en het beheer over haar oude koloniën opgedragen aan een 'Raad over de coloniën in America en over de besittingen in Africa' in den Haag. De Societeit van Suriname en de Directie van Berbice waren niet in de liquidatie begrepen en beide kolonies bleven nog tot I795 onder de bestaande particuliere directies bestaan. In genoemd jaar werden ook deze twee directies 'vernietigd' op grond van de overweging, dat een drieledige behering van de bezittingen in de West "tot groot nadeel van de colonien en tot merkelijk bezwaar der kosten" was. Suriname werd toen met alle andere koloniën in West-Indië onder bestuur gesteld van een 'Committé tot de zaken van koloniën en bezittingen op de kust van Guinea en in America'.

Door de ontbinding van de Societeit was Suriname dus onder het direct gezag van de Nederlandse Staat gekomen, waar kort 
tevoren de 'Bataafsche vrijheid' haar intrede had gedaan. Alle officieren en hoge ambtenaren in Suriname werden opnieuw beedigd en moesten nu trouw zweren aan de patriottische StatenGeneraal en aan het Committé. Bij de omzetting van de Republiek der Verenigde Nederlanden in een Bataafse Republiek in I796 bleef het Committé 'namens het volk' de administratie voeren. Gouverneur FRIDERICI en alle ambtenaren bleven echter in functie en een nieuwe bestuursregeling kwam niet tot stand, terwijl door het uitbreken van de oorlog met Engeland in 1796 het contact tussen Suriname en Nederland vrijwel werd verbroken. Het bestuursstelsel bleef daardoor formeel op oude grondslag berusten, terwijl er ook geen merkbare wijzigingen in de gevormde bestuurspraktijk werden aangebracht. De achteruitgang van de invloed der koloniale Raden zette zich voort.

In I799, toen Suriname moest capituleren voor een sterke Engelse oorlogsvloot, werd de kolonie onder 'protectie' van de Koning van Engeland gesteld. Suriname was dan ook geen bezitting van Engeland geworden, hoewel de ingezetenen werden ontheven van hun eed aan de Republiek en een nieuwe eed van trouw aan de Engelse Koning moesten afleggen. De Gouverneur en Raden bleven voorlopig namens een onbepaalde Landsheer het bewind voeren totdat bij de vrede zou worden bepaald aan welke mogendheid Suriname zou worden toegewezen. In rooz werd bij de vrede van Amiens bepaald, dat Suriname weer aan Nederland zou worden teruggegeven. Het bestuur werd door deze Staat nu opgedragen aan een 'Raad der Americaansche Coloniën en Bezittingen der Bataafsche Republiek'. Deze Raad handhaafde de Gouverneur niet en stelde een 'provisioneel Gouvernement' in diens plaats.

Het provisionele gouvernement heeft maar een bijzonder kort leven gehad. In I804 brak opnieuw oorlog met Engeland uit en nog in het zelfde jaar moest Suriname onvoorwaardelijk capituleren. De kolonie werd nu namens de Koning van Engeland in bezit genomen als Crown colony. Er was nu dus geen sprake meer van 'protectie'. De gelden in de Landsheerlijke kassen (Sovereign Chest) werden verder regelmatig naar de Treasury in Londen geremitteerd ondanks de precaire toestand van de koloniale kassen (Colony Chest). Engelse gouverneurs werden aangesteld, die evenwel op de oude voet het bestuur bleven uitoefenen. In tegenstelling met hun houding in de naastgelegen veroverde Nederlandse koloniën Demerary, Essequebo en Berbice hebben de 
Engelsen in Suriname nooit ernstig beproefd om de kolonie van Nederland te vervreemden. Een Oranjegezind Nederlander was zelfs geruime tijd met het gouverneurschap belast. Men speculeerde echter wel op een blijvend bezit van Engeland en een vrij groot aantal Engelse kolonisten, vooral Schotten, kwam zich toen in Suriname, met name in het Opper- en Neder-District Nickerie, vestigen.

Overeenkomstig de Londense Conventie van I8I4 zou Suriname toch weer aan Nederland worden teruggegeven. Aangezien Suriname volgens Engelse begrippen een bezitting was van de Koning, geschiedde deze teruggave niet aan de nieuwe Nederlandse staat, maar aan Koning Willem I persoonlijk. Men was blijkbaar ook in Nederland als reactie op de Napoleontische tijd weer bijna geheel teruggevallen in de oude sfeer van vóór de Franse revolutie, toen het staatsgezag, althans over de koloniën, werd beschouwd als een vermogensrecht van de vorst. Koning WILLEM I werd als souverein vertegenwoordiger van het Rijk zodoende de nieuwe Landsheer van Suriname. Hij verenigde dus in $\mathrm{Zijn}$ persoon de betrekkelijke bevoegdheden van de vroegere Staten-Generaal én de Societeit. Volgens de nieuwe Grondwet werd het opperbestuur over de volksplantingen en bezittingen van het Rijk in andere werelddelen bij uitsluiting opgedragen aan de Koning. Een delegatie van bevoegdheden aan afzonderlijke bestuurscolleges als voorheen vond daarom niet meer plaats. Het bestuur over Suriname zou voor geruime tijd rechtstreeks door de Koning worden gevoerd middels de aan Hem verantwoordelijke Minister van Koloniën.

Toen in I8I6 de daadwerkelijke overdracht van Suriname aan de Nederlandse Gouverneur plaats vond, trad het bij Koninklijk besluit vastgestelde Regeringsreglement van $18 \mathrm{I}_{5}$ in werking. Uitgaande van het standpunt, dat de kolonie niet meer tegen een particuliere handelsonderneming diende te worden beschermd, werd met dit staatstuk een einde gemaakt aan de autonomie, die zich onder het octrooi van 1682 in Suriname had ontwikkeld. Dit gebeurde zelfs zonder dat hiertegen werd geprotesteerd. De Politieke Raad verloor de zelfstandige bevoegdheden, die zij eertijds had bezeten. Weliswaar bleef deze Raad nog belast met het bestuur over de huishoudelijke en plaatselijke belangen, maar haar "keuren en plaatselijke wetten" behoefden voortaan niet alleen de goedkeuring des Konings, maar werden door de Koning gestatueerd. Alle bevoegdheden van het Hof konden 
zodoende door de Landsheer weer aan zich worden getrokken en dit gebeurde ook een tiental jaren later inderdaad. Bij het Regeringsreglement van 1828 werd het Hof van Politie tot een zuiver rechterlijk orgaan teruggebracht in verband met het beginsel van scheiding van machten. Het Hof van Civiele Justitie was reeds in I8I6 ontbonden met gelijktijdige instelling van een rechterlijk college onder dezelfde naam met gegradueerde leden. In I828 werd de algehele rechtspleging in handen gelegd van een Hof van Civiele en Criminele Justitie, waarvan de President en 4 leden meester in de rechten moesten zijn en 2 leden ingezetenen, die niet gegradueerd behoefden te zijn. Daarmee waren de eens zo belangrijke koloniale Hoven geruisloos van het toneel verdwenen. Toen in I845 ingezetenen, die niet gegradueerd waren, in het geheel niet meer in aanmerking konden komen voor de functie van rechter of griffier bij het Hof, had ook de lekenrechtspraak van ingezetenen volledig een einde genomen.

Het verlies van de vroegere autonomie kwam vooral tot uiting in het verlies van eigen geldmiddelen. De koloniale kassen, zoals de Cassa der Modique Lasten voor de betaling van predikanten, schoolmeesters en weduwen, de Cassa van de Gemeene Weide voor het toezicht op de erven enz. van Paramaribo, het bruggenen weggeld voor publieke werken, de Wegloperskas voor de strijd tegen de marrons, de Contributiekas voor verdedigingswerken, de kerkelijke contributie enz. kwamen nu met de eigenlijke Landsheerlijke belastingen tezamen terecht in een algemene Koloniale Kas, een Rijkskas, waaruit in de eerste plaats de kosten van het bestuur van Suriname dienden te worden bestreden. Van een batig slot was daarbij overigens nooit sprake.

Bij het Regeringsreglement van 1828 werden, ter besparing van de kosten, de West-Indische koloniën administratief verenigd onder een Gouverneur-Generaal, die werd bijgestaan door een Hoge Raad, bestaande uit enkele belangrijke ambtenaren. Bij de invoering van de 'nieuwe orde op zaken' werd het oude 'Collegie van de Gemeene Weide', een commissie uit het Hof van Politie, belast met de aangelegenheden betreffende Paramaribo, tegelijk met de laatste restanten van het Hof opgeheven. Daarvoor in de plaats werd een Gemeente Paramaribo ingesteld met een bestuur, bestaande uit een President en 2 wethouders, te benoemen door de Koning, en 8 raadsleden, te benoemen door de Gouverneur-Generaal. Voor de eerste maal werden allen benoemd, doch periodiek zou aftreding plaats vinden en bij nieuwe benoemingen zou dan door de Gouverneur-Generaal een keuze 
worden gedaan uit een door het Gemeentebestuur zelf gedane voordracht van een dubbeltal voor iedere plaats. Alleen 'bekwame en geschikte' ingezeten burgers kwamen in aanmerking. De Gemeenteraad werd belast met het administratieve beheer der plaatselijke aangelegenheden en had met alle huishoudelijke belangen der Gemeente te maken. Een omstandig uitgewerkt programma van werkzaamheden werd reeds bij de instelling opgesteld. Aan de eerste Wethouder werd het toezicht op de stadspolitie opgedragen. Tot zelfs buiten Paramaribo strekte de invloed van de Raad zich uit, althans op papier, want voor ieder buitendistrict zouden uit de leden van de Raad 2 Heemraden worden benoemd.

Er was dus toch nog na de opheffing van het Hof van Politie een zekere vorm van medezeggenschap in het bestuur voor de ingezetenen geschapen, maar deze was wel bijzonder gering. Uitdrukkelijk werd bovendien bepaald, dat het Gemeentebestuur 'volkomen ondergeschikt' was aan de Gouverneur-Generaal en aan de hoge autoriteiten van de kolonie. De nieuwe instelling heeft overigens nauwelijks de tijd gekregen om zich te ontwikkelen. Reeds na 4 jaar, in 1832 , werd de Gemeente weer opgeheven en werd de taak ervan overgenomen door het ambtelijk apparaat.

Het Regeringsreglement van 1832 bracht, in de plaats van het doodgeboren Gemeentebestuur, opnieuw een vorm van zeer beperkte inschakeling van geselecteerde ingezetenen bij het bestuur van Suriname. Er werd namelijk aan de GouverneurGeneraal een Koloniale Raad toegevoegd, waarin een tweetal ambtenaren functioneel zitting had, maar verder ook 6 van de aanzienlijkste ingezetenen van Suriname. Deze ingezetenen dienden voor een deel in de kolonie woonachtige grondbezitters te zijn en voor het overige deel vertegenwoordigers van afwezige grondbezitters. Om het jaar zou één dezer leden aftreden. Voor de vacature zou door de Koloniale Raad een voorstel van drie personen worden gedaan, waaruit dan de Gouverneur-Generaal een keuze deed.

De Koloniale Raad was ingesteld 'met geen andere oogmerken' dan om de Gouverneur-Generaal te adviseren en voor te lichten. Geen andere onderwerpen konden op de agenda van de raadsvergaderingen worden gebracht dan die door de GouverneurGeneraal voorgedragen. Suriname was, staatkundig gesproken, op het diepste punt aangeland. In de instructie van de Gouver- 
neur-Generaal werden voorts diens bevoegdheden nog nader uitgewerkt. In die van 1833 werden hem bovendien strikte richtlijnen gegeven voor zijn bestuur. Er stond o.m.: "Voor zooveel de Kolonie Suriname betreft zal hij zooveel doenlijk de zaken beknoptelijk afdoen met vermijding van alle omslagtige schrifturen. Hij zal in het algemeen alles wat van hem afhangt in het werk stellen, om aan de ingezetenen van Suriname een eenvoudig bestuur te doen ondervinden, ontdaan van al die formaliteiten, welke slechts in koloniën van eenen grooteren omvang noodig en passend, in kleine bezittingen daarentegen overtollig en belemmerende zijn". De belangstelling van Nederland was trouwens door de zeer slecht geworden economische toestand en vooruitzichten practisch tot nul gereduceerd.

De verenigde administratie van Suriname en de Antillen voldeed niet en bij het Regeringsreglement van I845 werd het bestuur wederom gescheiden. Suriname kreeg dus weer een eigen Gouverneur, maar de politieke situatie veranderde verder nauwelijks. Alleen werd nog bepaald, dat in de regel in elk district het Heemraadschap zou worden waargenomen door een lid van de Koloniale Raad benoemd uit de ingezetenen. Verder dienden alle notulen van de vergaderingen van de Raad in het vervolg naar Nederland te worden gezonden tot voorlichting van de Minister van Koloniën. Intussen had zich echter in Nederland bereids een verandering van denkbeelden omtrent het koloniaal bezit voltrokken. Men ging de koloniën nu eindelijk wat meer beschouwen als delen van het Rijk, waarvoor de volksvertegenwoordiging in Nederland de verantwoordelijkheid droeg, inplaats van min of meer privé domein van de Koning. De StatenGeneraal eisten in de eerste plaats bemoeienis met de koloniale begrotingen, hetgeen bij de Grondwetswijziging van 1840 werd geregeld. Daar het opperbestuur bij de Koning bleef berusten werd het Regeringsreglement van I845 toch nog bij Koninklijk besluit vastgesteld.

Juist in het jaar I845 dienden G. C. Bosch ReItz en 45 andere Amsterdamse kooplieden bij de Tweede Kamer een verzoekschrift in over Surinaamse aangelegenheden, waarover nogal wat te doen is geweest. Op haar verzoek werd de Kamer uitvoerig over deze kwestie ingelicht door de Minister van Koloniën BAUD, die van oordeel was, dat in de Regeringsreglementen de waarborgen aanwezig waren, welke door de kolonie waren 'bedongen' bij het Surinaams octrooi van I682, die "haar konden beveiligen tegen willekeurig bestuur en tegen aanranding van personen en 
goederen door den opperbewindvoerder". De Kamer was echter geenszins bevredigd door de inlichtingen, die naar aanleiding van het adres waren verstrekt. Niemand minder dan de grote Thorbecke bepleitte in de Kamer het treffen van een wettelijke regeling voor Suriname "opdat de inrichting, door het Octrooi van 1682 gevestigd, wettig en naar de eisch van de tegenwoordige tijd kunne worden veranderd". De Commissie uit de Kamer durfde het gezag der Koninklijke besluiten, waarbij de Regeringsreglementen voor Suriname waren vastgesteld, niet hoger schatten dan dat zij "het Octrooi althans facto hebben vervangen en buiten werking gesteld". Eindelijk begon men zich dus weer het bijzondere octrooi te herinneren en realiseerde men zich in Nederland, dat men wat Suriname betreft toch wel belangrijk uit de koers was geraakt.

$\mathrm{Bij}$ de herziening van de Grondwet in 1848 kregen de StatenGeneraal tenslotte de bevoegdheid aan de wetgeving van de koloniën deel te nemen. Voor de reglementen op het beleid der regering in de koloniën werd nu een wet verlangd en de Kroon was gehouden de Staten-Generaal jaarlijks omstandig voor te lichten over het bestuur van de koloniën en de staat, waarin deze zich bevonden.

Hoewel binnen 3 jaar na de afkondiging van de nieuwe Grondwet het ontwerp van wet moest worden ingediend, heeft de totstandkoming van het Regeringsreglement veel langere tijd gevorderd. Uiteindelijk wilde de Regering ermee wachten totdat de emancipatie der slaven een feit was geworden. Daardoor bereikte het Regeringsreglement, nu een wet, pas in I 865 het staatsblad. Met dit Regeringsreglement werd Suriname opnieuw een beperkte autonomie verleend. Als vertegenwoordigend lichaam werden de Koloniale Staten ingesteld, bestaande uit 4 benoemde en tenminste 9 rechtstreeks gekozen leden. Deze Staten kregen het recht van initiatief en amendement. De uitvoerende macht bleef volledig berusten bij de Gouverneur, bijgestaan door een adviserende Raad van Bestuur.

"Autonomie ware een ijdele klank zonder zeggen over eigen finantiën" waren de woorden van Minister FRANSSEN VAN DE PuTte in de Memorie van Toelichting op het ontwerp. Het onderscheid tussen de koloniale geldmiddelen en de Rijksschatkist werd nu weer uitdrukkelijk erkend en Suriname kreeg een betrekkelijk grote zelfstandigheid om over eerstgenoemde gelden ten behoeve van de openbare dienst te beschikken. Maar omdat 
de zwakke financiële positie van het Land in de volgende jaren regelmatig een Rijkssubsidie nodig maakte, kwam de in 1865 verkregen zelfstandigheid ruim driekwart eeuw niet tot haar recht. Deze zelfstandigheid was niettemin zodanig, dat Suriname als rechtspersoon diende te worden beschouwd. Hoewel dit niet met zoveel woorden in de wet is gezegd, blijkt het o.a. uit de woorden van de Minister zelf, die in de Memorie van Toelichting van het ontwerp-regeringsreglement stelde: "De zelfstandigheid door de kolonie te verkrijgen verheft haar publiek- en privaatrechtelijk tot een van den Staat onderscheiden rechtspersoon".

De verdere staatkundige ontwikkeling van Suriname mag als bekend worden verondersteld. Via de Staatsregelingen van 1936 en I948, de Interimregeling van I950, het Statuut van I954 en de Staatsregeling van I955 is Suriname geworden tot een zelfstandig partner in het Rijksverband. Het is bij de beoordeling van deze laatste ontwikkeling van belang zich te realiseren, dat de voorgeschiedenis niet zulk een geleidelijk oplopende lijn te zien geeft als gemeenlijk in Suriname en in Nederland wordt verondersteld.

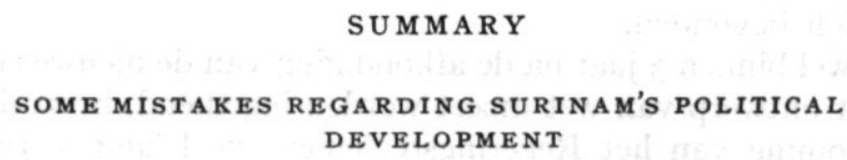

It is generally supposed that Surinam's political development has gradually proceeded from complete colonial dependence to internal autonomy after the proclamation of the Statute of the Kingdom of the Netherlands in December 1954.

The author disproves this contention, and shows that in the 17 th and I 8 th centuries Surinam enjoyed a political autonomy, which was very remarkable at so early a period in the history of colonialism.

It was only towards the end of the $\mathrm{r} 8$ th century that Surinam gradually lost her independent status. This process was hastened by the crash of the Amsterdam Exchange in 1773. As a result of the dissolution of the "West-Indische Compagnie" in 1792, Surinam came under direct administration of Holland.

The state of total dependence lasted for some time, and only from the second half of the rgth century, Surinam began to achieve limited political rights step by step. After a stormy development due to the Second World War, Surinam emerged as an autonomous partner in the Kingdom of the Netherlands. 